H.-S. in that the fore wings are much darker. The male has no white markings except the apical streak, and the transverse lines, usual in the Notodontidae, can be seen faintly crossing the wing, while in $P$. dimidiata they are quite obsolete except at the internal margin. T. a. line very faint, defined by the inner edge of the black cellular patch, obso- lete below median vein, but below submedian fold very distinct, white, sharply produced inward and bordering the fawn colored patch. T. p. line from costa along discal cross vein, either straight or sharply dentate on the veins, lost between veins 2 and 3 , but distinct on internal margin in a short white dash, reaching internal vein.

\title{
OVIPOSITION OF A HOMOPTEROUS INSECT IN YUCCA.
}

\author{
BY C. H. TYLER TOWNSEND, LAS CRUCES, N. MEX.
}

On May 15, I89r, a grayish homopterous insect, one of the Fulgoridae, or lantern-flies, was found very numerous on leaves of rucca angustifolia. It was also found on $r$. macrocarpa (?)*. Specimens are determined by Dr. Uhler as Oecleus decens Stål.

At the same daze on which the insects were found, it was noticed that the leaves of $r$. angustifolia were largely covered with very small patches of a pure white, woolly or cottony, fluffy material, arranged in more or less irregular rows. They were found to be punctures consisting of slightly raised swellings of the surface of the leaf, each swelling being marked by this cottony covering. They exhibited much the general appearance, at first sight, of colonies of a small white cottony scale. These are the egg-punctures. They are always placed on the upper side of the leaf, and usually, if not always, near the tip or point. Superficial examination shows only this woolly, snow-white, fluffy substance, apparently containing nothing, but covering the slightly raised puncture in the leaf. The above fulgorid was found wherever this woolly material occurred, usually on and about it, and consequently raised the question in my mind of some connection between the two.

On May 2I, the punctures were carefully examined and found to contain eggs. The

* This species may be $Y$. baccata. egg measures $\frac{4}{5} \mathrm{~mm}$. in length, by $1 \mathrm{~mm}$. in width. Examination on May ${ }_{5}$ had disclosed no eggs whatever, and I imagine that they were not yet all deposited at that date. The presence of the insects would perhaps indicate that they were in the act of ovipositing and preparing the leaves for the reception of the eggs. The leaves of $r$. macrocarpa (?) contained, at that date, no punctures. Though I have not at any time observed the insects making these punctures, I still feel confident that the latter belong to this fulgorid, since there is no other insect frequenting the Yuccas that could make them. I may add that $I$ have found the abdominal saws or pincers of a female specimen with some of the same white fluffy substance still adhering to them.

On May 3I, plants of rucca augustifolia were found to be thickly oviposited in. Some plants had the tips of nearly every leaf covered with the white fluffy material. Numbers of this insect were present, many of them on the punctured portions.

On June 2, similar egg punctures were found on the leaves of rucca macrocarpa (?) marked by the same woolly material. Three specimens of an Oecleus, which Dr. Uhler says is the same as $O$. decens, were found clustered on the woolly punctures. They were, however, decidedly smaller than those previously found, and which had occurred only on $r$. angustifolia. I was inclined to 
consider them a distinct species, since they were of uniform size among themselves. Only one specimen of this smaller kind had been found before this date, but it was taken, May 30 , on an isolated plant of $r$. angustifolia, alone and solitary. I will therefore not attempt to prove any distinction between the two forms, which may be only the two sexes of the same species, and apparently are from an examination of the genitalia.

The punctures are sometimes placed in rows, but usually only when near the tips of the narrow leaves of $r$. angustifolia. They are most often massed together over the whole upper distal surface of the leaf, and are always placed very closely together. Each patch or tuft of the cottony substance which marks a puncture is usually from $\frac{4}{5} \mathrm{~mm}$. to $\mathrm{I} \mathrm{mm}$. in diameter, and about $\frac{2}{5} \mathrm{~mm}$. thick or slightly more.

This white, fluffy material is extremely fine in texture, and I was at first inclined to believe that it was simply the natural very fine and silken fiber of the Yucca leaf, carded out by the ovipositor of the female Oecleus. Were this so, it would be quite interesting as exhibiting in a state of nature the beautiful, delicate, silken fiber which these plants are capable of yielding. I believe, however, that it is a juice, either from the leaf or from the insect, probably the former, which hardens on exposure to the air. It is seemingly soluble in water, and is probably only the hardened sap of the Yucca leaf.

In conclusion, it might be said that the constant watchfulness with which the Oecleus seems to attend upon and frequent the vicinity of its egg-punctures, even after the eggs have for days been deposited, is suggestive of a motherly instinct and seems a manifestation of parental care in the hatching of the young.

\section{The Butterflies of the Eastern United States and Canada.}

With special reference to New England. By SAmuel H. Scudder.

Illustrated with 96 plates of Butterflies, Caterpillars, Chrysalids, etc. (of which $4 \mathrm{I}$ are colored) which include about 2,000 Figures besides Maps and Portraits. 1958 Pages of Text.

Vol. I. Introduction; Nymphalidae.

Vol. 2. Remaining Families of Butterflies.

Vol. 3. Appendix, Plates and Index.

The set, 3 vols., royal 8vo, half levant, $\$ 75.00$ net.

\section{HOUGHTON, MIFFLIN \& CO.,}

4 Park St., Boston, Mass.

R̈̈OPALOCERA.

Rhopalocera from Europe, New Grenada, Sikkim, Assam, Pulo Nias, British Guiana, Congo Free State and various Polynesian Islands. Correspondents will oblige by stating desiderata. No post cards.

DR. J. T. T. REED,

Ryhope, Sunderland, England.

ADVER TISEMENT.

Undersigned wishes to obtain either by exchange or for cash, Cicindelidae and rare Carabidae from all parts of the U.S. Lists please address to

A. LUETGENS,

207 E. I5 Street, N. Y. City.

\section{THE NEW ENGLAND SPIDERS.}

BY J. H. EMERTON.

In seven parts from the Transactions of the Connecticut Academy of Arts and Sciences Vols. VI, VII and VIII containing descriptions of 340 species with I400 figures.

Price for the whole $\$ 6.00$, or either part sold separately. Sent by mail on receipt of price.

\section{J. H. EMERTON,}

Boston, Mass. 

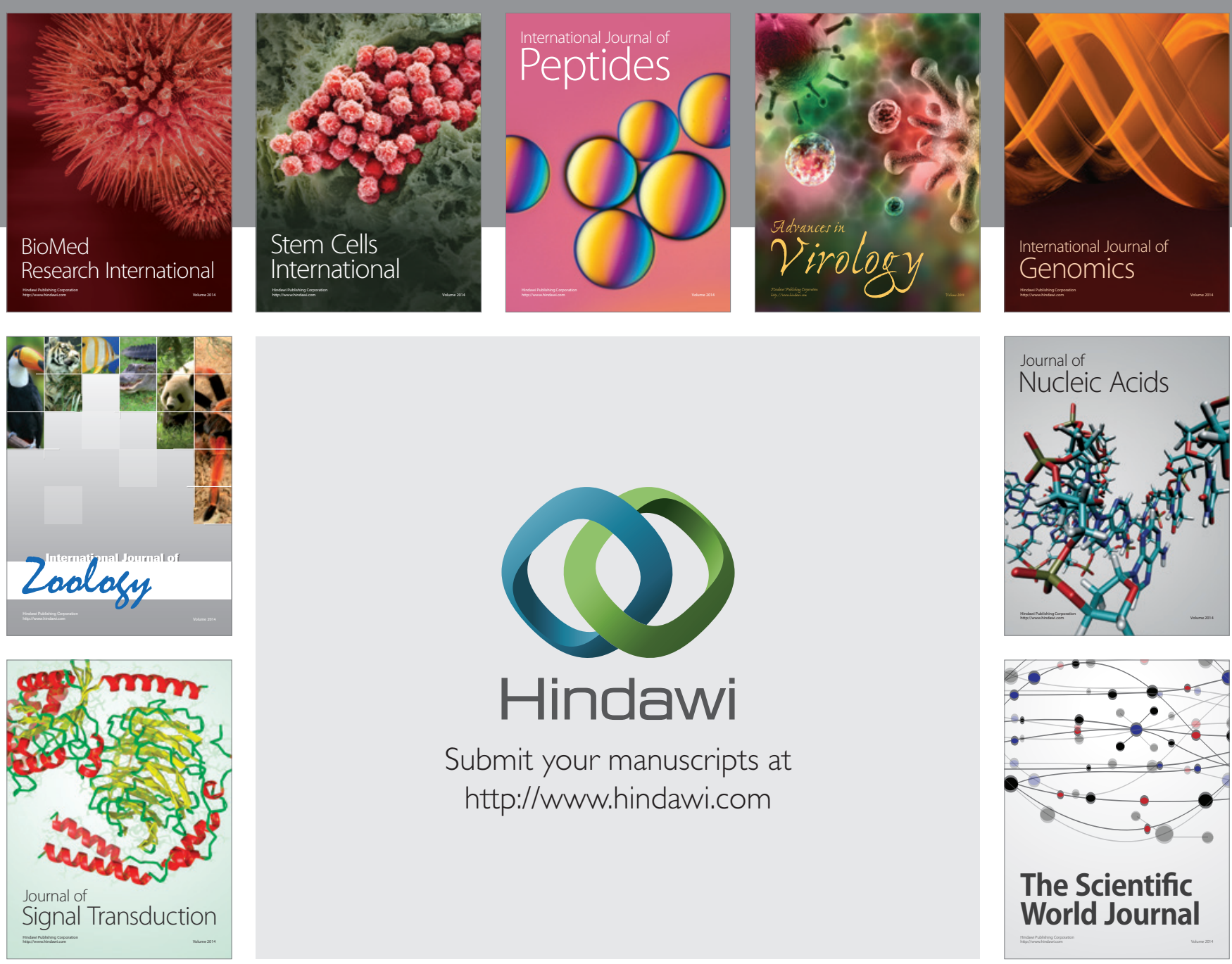

Submit your manuscripts at

http://www.hindawi.com
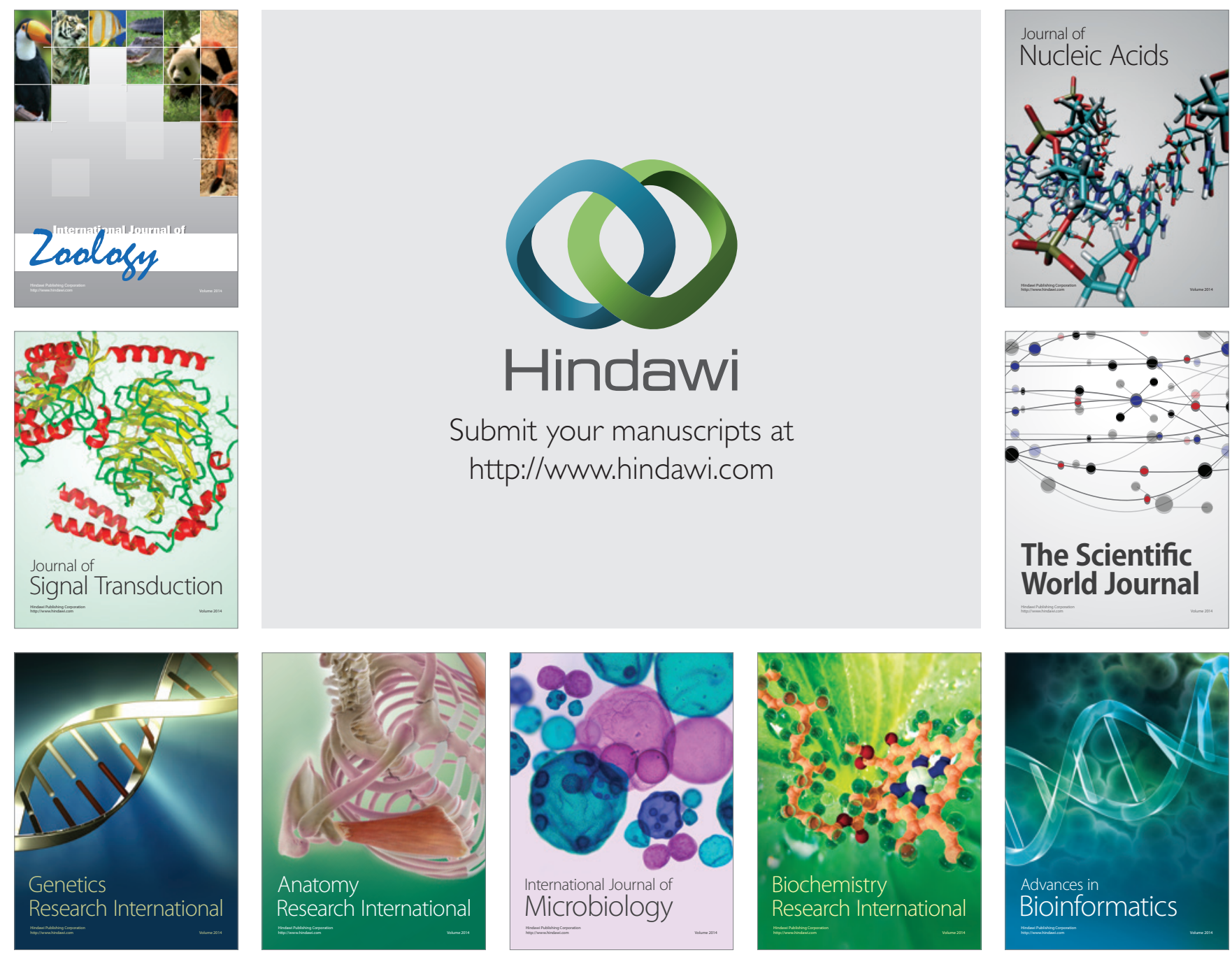

The Scientific World Journal
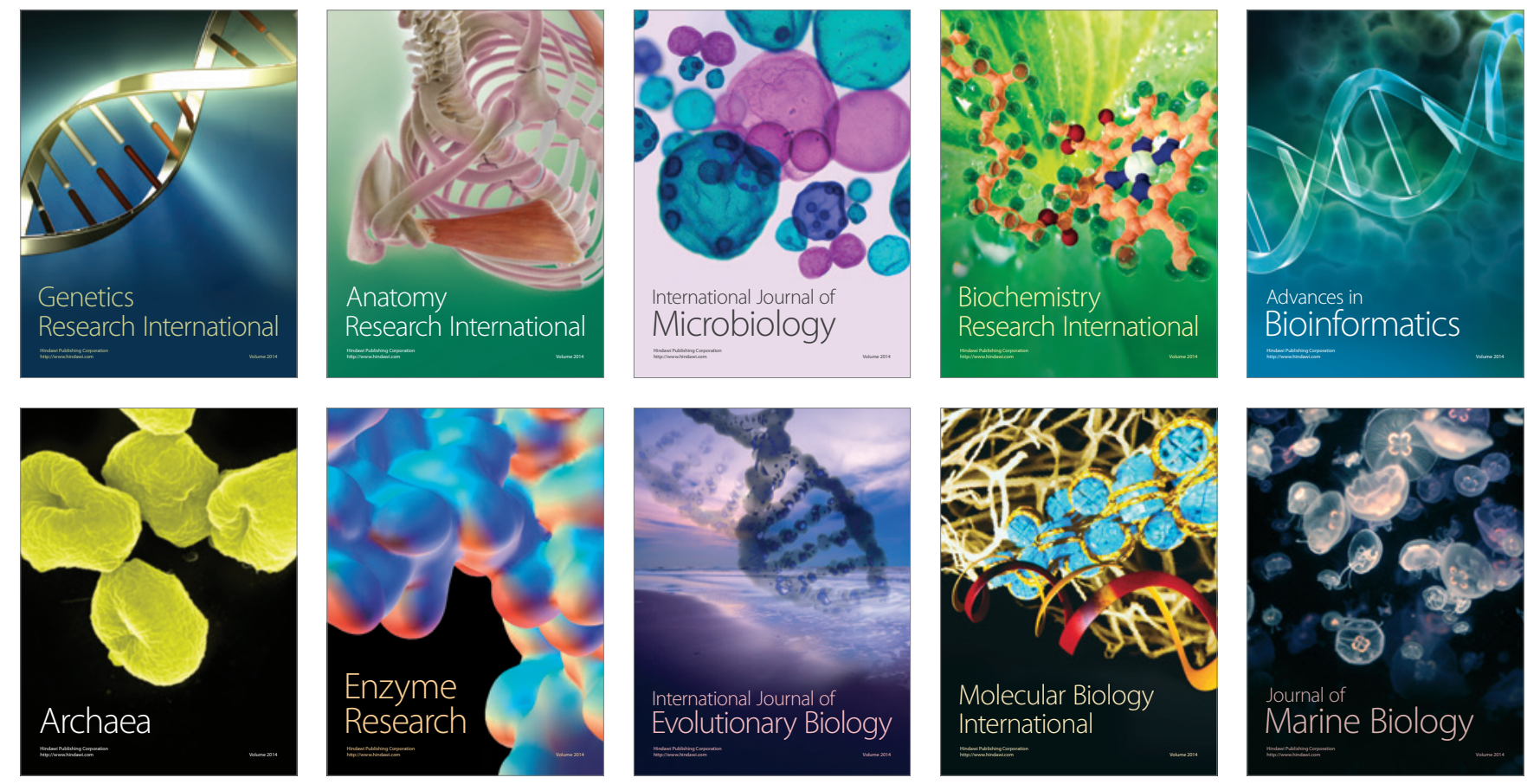